\title{
Effect of mifepristone (RU 486) on concentrations of prostaglandin E-2 binding sites in the rat endometrium
}

\author{
D. Martel, M. N. Monier, D. Roche and A. Psychoyos \\ Laboratoire de Physiologie de la Reproduction, Hôpital de Bicêtre, Bat. INSERM, \\ 78 rue du général Leclerc, le Kremlin Bicêtre 94270, France
}

\begin{abstract}
Summary. Progesterone implants in ovariectomized rats increased endometrial concentrations of PGE-2 receptors. The increase was completely inhibited by simultaneous daily injection $(7.5 \mathrm{mg} / \mathrm{kg}$ ) of mifepristone (RU 486). A single injection of mifepristone on the morning of Day 1 of pseudopregnancy (day of oestrus) decreased the amount of PGE-2 receptors found in the endometrium on Day 5 by $64 \%$. This inhibitory effect probably resulted from the antiprogesterone activity of this compound since it was not counteracted by simultaneous treatment with dexamethasone, shown to reverse totally the antiglucocorticoid action of mifepristone. The inhibition by mifepristone lasted only for 1 day; endometrial PGE- 2 receptor levels on Day 6 of pseudopregnancy returned to the high values present in controls. Under these conditions, administration of the mifepristone did not affect the plasma oestradiol and progesterone concentrations during the 1 st week of pseudopregnancy. The administration of mifepristone on Days 2 and 3 of pseudopregnancy kept the endometrial PGE-2 receptor levels low, even by 4 days after the end of treatment. We therefore concluded that, in the rat, progesterone priming leading to uterine receptivity can be delayed, at least by 1 day. In contrast, interruption of the progesterone action for a longer period later during the early pseudopregnant period resulted in an altered subsequent evolution of the endometrium, in terms of acquisition of the PGE-2 binding sites.
\end{abstract}

Keywords: implantation; mifepristone; PGE-2 receptor; endometrium; rat

\section{Introduction}

Successful implantation requires the synchronism of embryo development and uterine preparation (Psychoyos, 1973). The endometrium must reach a hormone-dependent and chronologically limited phase of receptivity. In the rat, a substantial increase in the concentration of binding sites for prostaglandin (PG) E-2 in the endometrium has been shown to coincide with the onset of uterine receptivity. The PGE-2 receptor content increases between Days 4 and 5 of pseudopregnancy (Kennedy et al., 1983a), and this increase is progesterone-dependent (Kennedy et al., 1983b). The administration of progesterone antagonists early in pregnancy or pseudopregnancy delays or prolongs the period of uterine receptivity in the rat (Sarantis et al., 1988) and the rabbit (Hegele-Hartung \& Beier, 1986). The present study was carried out to investigate: (1) the effect of the progesterone antagonist mifepristone (Philibert, 1984) on the induction of PGE-2 receptors in the endometrium of ovariectomized rats treated with progesterone and (2) the action of the administration of various series of injections of mifepristone early in pseudopregnancy on the endometrial PGE-2 receptor level as a marker of the onset of uterine receptivity. 


\section{Materials and Methods}

Radioactive PGE-2 [5,6,8,11,12,14,15-3H(N)] prostaglandin E-2 (sp. act. 150-200 Ci/mmol) was obtained from New England Nuclear Corporation, Boston, MA, USA. Unlabelled PGE-2, progesterone, dexamethasone, indomethacin, and BSA were purchased from Sigma Chemical Co., St Louis, MO, USA. The oestradiol and mifepristone (RU 486) were a gift from Roussel Uclaf, Romainville, France.

Experimental animals and treatments. Adult virgin female rats of the Wistar strain, weighing $200-220 \mathrm{~g}$, were housed under controlled illumination of 14-h light, 10-h darkness with 13:00 h as the mid-point of the light phase. Vaginal smears were recorded daily. After at least 2 regular oestrous cycles of 4 days, pseudopregnancy was induced by vaginal-cervical stimulation (De Feo, 1966) on the last day of oestrus. The appearance of leucocytes in the vaginal smear on the following day established that day as the second of pseudopregnancy. The rats were checked daily for the presence of vaginal leucocytes until the day they were killed.

When specified, animals were ovariectomized and given 4 days later a priming injection of oestradiol $(1 \cdot 25 \mu \mathrm{g} / \mathrm{rat}$ in $200 \mu \mathrm{l}$ sesame oil). After 2 days without treatment, 6 Silastic progesterone implants were placed subcutaneously. These were prepared according to the procedure described by Bridges (1984). The Silastic implants, cat. 602-305, Dow Corning Corporation (Midland, MI, USA) each measuring $3 \mathrm{~cm}$ in length contained crystalline progesterone. Such implants generate plasma progesterone concentrations in the same range as those measured during pregnancy in the rat (Bridges, 1984).

Mifepristone was suspended in sesame oil and administered subcutaneously in a volume of $0.2 \mathrm{ml} / \mathrm{rat}$. The animals received $7.5 \mathrm{mg}$ mifepristone $/ \mathrm{kg}$ or sesame oil.

Animals were killed by decapitation under ether anaesthesia.

Binding assay. Membrane preparation and PGE-2 binding assay were performed as previously described (Kennedy et al., 1983a). In summary, the homogenates were centrifuged at $700 \mathrm{~g}$ for $10 \mathrm{~min}$, the resulting supernatants were centrifuged at $10000 \mathrm{~g}$ for $45 \mathrm{~min}$. The $10000 \mathrm{~g}$ pellets were resuspended in buffer ( $100 \mathrm{~mm}$-sodium phosphate $\mathrm{pH}$, $100 \mathrm{~mm}$-sucrose, $10 \mu \mathrm{M}$-indomethacin, $12 \mathrm{~mm}$-monothioglycerol). Protein concentration in the membrane suspensions ranged from $\simeq 1$ to $2 \mathrm{mg} / \mathrm{ml}$. Membrane preparations were incubated $(\mathrm{v} / \mathrm{v})$ with increasing concentrations of $\left[{ }^{3} \mathrm{H}\right] \mathrm{PGE}-2$ ranging from 4 to $20 \mathrm{nM}$. The non-specific binding was assessed in a parallel incubation in which a 500 -fold excess of PGE-2 was added. The levels of radioactivity in non-specific binding samples were only slightly higher than those of the corresponding blanks, suggesting that non-specific binding was very low. The samples were incubated for $30 \mathrm{~min}$ at $37^{\circ} \mathrm{C}$. At the end of the incubation, the free prostaglandins were removed by filtration on Whatman glass microfibre filters $(\mathrm{GF} / \mathrm{C})$ followed by 2 washes with $10 \mathrm{ml}$ buffer. The filters were counted for radioactivity. The specific binding was calculated by subtracting the non-specific binding, and the results were plotted according to Scatchard (1949).

Plasma oestradiol and progesterone measurements. On the day of death, the trunk blood was collected in heparinized tubes. The plasma samples were twice extracted with ether and the steroid concentrations were estimated using a commercial radioimmunoassay (Centre de l'Energie Atomique, Saclay, France). For oestradiol determinations, the sensitivity of the assay was $1 \pm 0.2 \mathrm{pg} /$ tube, the intra-assay variation was $10.5 \pm 4.2 \%$ and the inter-assay variation was $18.4 \pm 7 \%$. For progesterone determinations, the sensitivity of the assay was $7 \pm 5 \cdot 1 \mathrm{pg} /$ tube, the intra-assay variation was $10.9 \pm 0.026 \%$ and the inter-assay variation was $25.1 \pm 0.063 \%$.

Protein determination. The concentration of protein in the endometrial membrane preparations was determined by the method of Lowry et al. (1951), using bovine serum albumin as standard.

Radioactivity determination. Filters were transferred into scintillation vials containing $10 \mathrm{ml}$ scintillation fluid $(4 \mathrm{~g}$ omnifluor (New England Nuclear) and $36 \mathrm{ml}$ acetic acid per litre toluene). Radioactivity was determined in a liquid scintillation spectrophotometer (LKB Instrument) and quenching was corrected automatically.

\section{Results}

\section{Effects of mifepristone in ovariectomized rats treated with progesterone}

In the group receiving mifepristone, animals were given daily injections of mifepristone starting on the day when progesterone implants were placed. Animals were killed 3 days after the start of the progesterone treatment. The control group received the priming injection of oestradiol only.

The progesterone induced a substantial increase in the endometrial PGE-2 receptor concentration (Table 1). Daily injection of mifepristone totally abolished the effect of progesterone. Mifepristone given alone had no effect on the PGE-2 receptor level. 
Table 1. Prostaglandin E-2 receptor content in the endometrium of ovariectomized rats having received a priming dose of oestradiol (control, Ovx), or of ovariectomized rats having received the priming dose of oestradiol and treated with progesterone (6 subcutaneous implants) and/or injected with mifepristone $(7.5 \mathrm{mg} / \mathrm{kg})$

\begin{tabular}{lcc}
\hline & $\begin{array}{c}\text { Dissociation } \\
\text { constant } \\
\text { (nM) }\end{array}$ & $\begin{array}{c}\text { Binding } \\
\text { sites } \\
\text { conc. } \\
\text { (fmol/mg } \\
\text { protein) }\end{array}$ \\
\hline Control (Ovx) & n.d. & n.d. \\
$\begin{array}{l}\text { Ovx + progesterone } \\
\text { Ovx + progesterone } \\
\quad \text { + mifepristone }\end{array}$ & $5 \cdot 55 \pm 0 \cdot 14$ & $105 \cdot 20 \pm 8 \cdot 62$ \\
Ovx + mifepristone & n.d. & n.d. \\
\hline
\end{tabular}

Values are means \pm s.d. for determinations performed on 21 animals per time point. n.d., Not detectable.

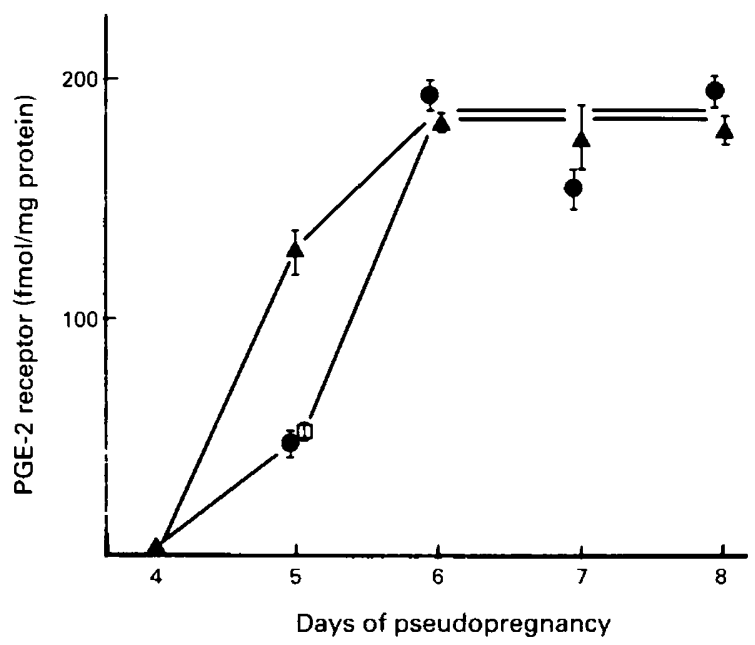

Fig. 1. Prostaglandin E-2 receptor content in the endometrium of pseudopregnant rats $(\Delta-\Delta)$, or of pseudopregnant rats after a single injection of mifepristone $(7 \cdot 5 \mathrm{mg} / \mathrm{kg})$ on the day of oestrus (-). One group killed on Day 5 of pseudopregnancy received a subcutaneous injection of dexamethasone $(1.25 \mathrm{mg} / \mathrm{kg})(\square)$ concomitantly with the mifepristone. Values are mean \pm s.d. of determinations performed on 21 animals per time point.

\section{Effects of mifepristone in pseudopregnant animals}

Pseudopregnant rats were given a single subcutaneous injection of mifepristone on the day of oestrus (Day 1 of pseudopregnancy). One group received, subcutaneously, a dose of dexamethasone $(1.25 \mathrm{mg} / \mathrm{kg})$ which has been shown to reverse totally the antiglucocorticoid effect exerted by $10 \mathrm{mg} / \mathrm{mifepristone} / \mathrm{kg}$ (Philibert, 1984).

PGE-2 receptor content in the endometrium (Fig. 1) increased on Day 5 of pseudopregnancy to reach a maximal level on Day 6, which was maintained until Day 8 of pseudopregnancy. The 


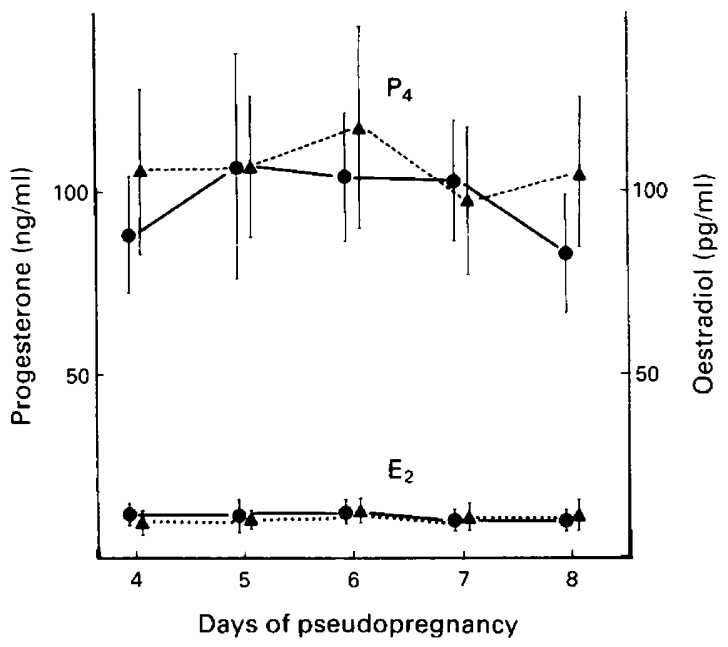

Fig. 2. Pattern of plasma oestradiol $\left(\mathrm{E}_{2}\right)$ and progesterone $\left(\mathrm{P}_{4}\right)$ concentration in pseudopregnant rats $(-)$ or in pseudopregnant rats after the injection of mifepristone $(7.5 \mathrm{mg} / \mathrm{kg})$ $(\boldsymbol{\Delta}---\boldsymbol{\Delta})$ on the day of oestrus (Day 1 of pseudopregnancy). Values are mean \pm s.d. of determinations performed on 21 animals per time point.

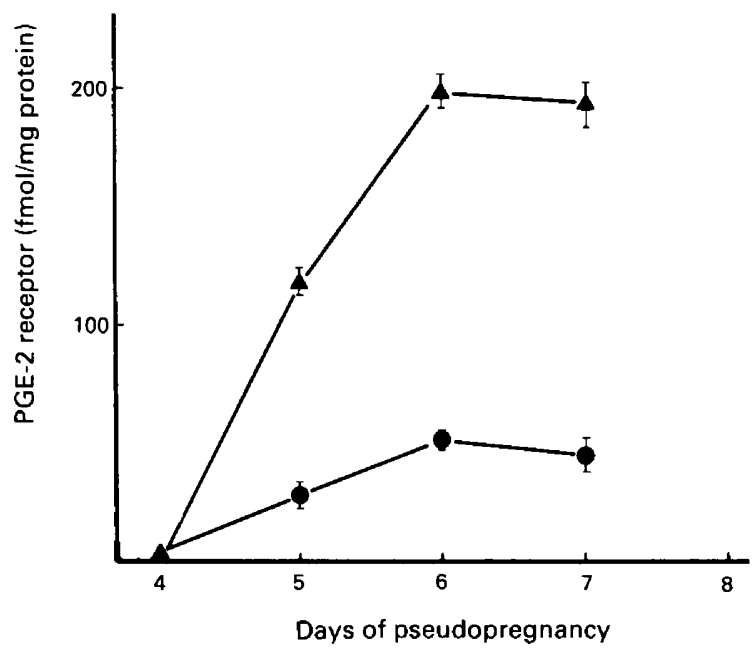

Fig. 3. Prostaglandin E-2 receptor content in the endometrium of pseudopregnant rats $(\Delta-\Delta)$, or of pseudopregnant rats after the injection of mifepristone $(7.5 \mathrm{mg} / \mathrm{kg}$ ) on Days 2 and 3 of pseudopregnancy $(-)$ ). Values are the mean \pm s.d. of determinations performed on 21 animals per time point.

injection of mifepristone resulted in a partial inhibition $(\simeq 64 \%)$ of the endometrial PGE-2 receptor level measured on Day 5 of pseudopregnancy; this effect was not reversed by the simultaneous injection of dexamethasone. On Day 6 of pseudopregnancy the endometrial content of PGE-2 receptor in the treated rats had returned to the same high levels measured on Days 6, 7 and 8 of control pseudopregnant groups. The experiment has been repeated twice with similar results. 
Figure 2 shows that the single injection of mifepristone on the day of oestrus did not modify the pattern of plasma oestradiol and progesterone concentrations in pseudopregnant rats.

Mifepristone administered on Days 2 and 3 of pseudopregnancy provoked a prolonged decrease ( $\simeq 75 \%$ inhibition) of the endometrial PGE-2 receptor levels measured on Days 5,6 and 7 of pseudopregnancy (Fig. 3).

\section{Discussion}

Our observations on the endometrium of ovariectomized rats indicate that the production of progesterone-induced PGE-2 binding sites is fully inhibited by simultaneous treatment with mifepristone, a progesterone and glucocorticosteroid antagonist. The $100 \%$ inhibition indicates that mifepristone is devoid of an agonistic effect. The inhibitory effect on endometrial PGE-2 binding most probably results from the antiprogesterone effect of the compound, since on Day 5 of pseudopregnancy the effect of mifepristone was not overcome by simultaneous injection of dexamethasone. These findings support our previous observations on the progesterone dependency of the PGE-2 receptor in rat endometrium. Philibert et al. (1985) noted a 100\% inhibition in deciduomata formation after treatment with mifepristone in the rat. Taken together, these findings suggest a high correlation between the presence of PGE-2 receptors in the endometrium and the ability of the endometrium to undergo decidual differentiation.

The present results for pseudopregnant animals confirm our previous observations showing that the appearance of the PGE-2 binding sites in the rat endometrium coincides with the onset of uterine receptivity for implantation. A single injection of mifepristone on Day 1 of pregnancy has been reported to postpone the phase of uterine receptivity by 1 or 2 days (Psychoyos \& Prapas, 1987; Sarantis et al., 1988). Our present results support this observation. Injection of mifepristone on the morning of Day 1 of pseudopregnancy reduces the level of PGE-2 binding sites in the endometrium on Day 5 of pseudopregnancy (the day of maximum uterine sensitivity) by $64 \%$. This inhibition only lasts for 1 day and on Day 6 the PGE-2 receptor value in mifepristone-treated rats returns to that of controls. The fact that the endometrial PGE-2 receptor concentration in treated rats is low but not negligible on Day 5 of pseudopregnancy, added to the observation that implantation is delayed in these conditions (Psychoyos \& Prapas, 1987), suggests that a threshold level of PGE-2 receptors in the endometrium must be reached before implantation can occur.

Our findings show that PGE-2 receptor production during the peri-implantation period (Day 5 of pseudopregnancy) is triggered by one or several progesterone-dependent events occurring about Day 1 or 2 of pseudopregnancy. A short interruption in the progesterone action on the day of oestrus does not interrupt the sequence of events leading up to uterine receptivity but simply delays it. This observation supports the work of Hegele-Hartung (1986) concerning the delayed secretion of uteroglobin in rabbit endometrium after treatment with the antiprogestagen ZK 98,734. However, when mifepristone is administered for 2 days, later in the pseudopregnant period on Days 2 and 3, the PGE-2 receptor level remains largely inhibited even 4 days after the end of the treatment, indicating that, in contrast to the preceding situation, the progesterone antagonist had interfered with the normal subsequent development of the endometrium.

Modifications in ovarian activity occur in the rat after long-term treatment with mifepristone (Van der Schoot et al., 1987), although our results indicate that a single injection of mifepristone on the day of oestrus does not interfere with ovarian steroidogenesis in early pregnancy.

In conclusion this study gives further evidence that, in specific conditions, mifepristone may be considered as potentially useful for controlling the time of uterine sensitivity for implantation.

We thank Dr D. Philibert of the Centre de Recherche Roussel-Uclaf for providing the mifepristone. This work was supported by the Centre National de la Recherche Scientifique, the Université Paris XI UER Médicale du Kremlin Bicêtre and the Rockefeller Foundation. 


\section{References}

Bridges, R.G. (1984) A quantitative analysis of the role of dosage, sequence and duration of estradiol and progesterone exposure in the regulation of maternal behavior in the rat. Endocrinology 114, 930-940.

De Feo, V.J. (1966) Vaginal cervical vibration: a simple method for the induction of pseudopregnancy in the rat. Endocrinology 79, $440-443$.

Hegele-Hartung, C. \& Beier, H.M. (1986) Distribution of uteroglobin in the rabbit endometrium after treatment with an antiprogesterone (ZK 98.734): an immunocytochemical study. Hum. Reprod. 1, 497-505.

Kennedy, T.G., Martel, D. \& Psychoyos, A. (1983a) Endometrial prostaglandin E2 binding: characterization in rat sensitized for the decidual cell reaction and changes during pseudopregnancy. Biol. Reprod. 29, 556-564.

Kennedy, T.G., Martel, D. \& Psychoyos, A. (1983b) Endometrial prostaglandin $\mathrm{E}_{2}$ binding during the estrous cycle and its hormonal control in ovariectomized rats. Biol. Reprod. 29, 565-571.

Lowry, O.H., Rosebrough, N.J., Farr, A.R. \& Randall, R.J. (1951) Protein measurement with the Folin phenol reagent. J. biol. Chem. 193, 265-275.

Philibert D. (1984) RU 38 486: an original multifaceted antihormone in vivo. In Adrenal Steroid Antagonism, pp. 71-101. Ed. M. K. Agarwal. Walter de Gruyter and Co., Berlin.
Philibert, D., Moguilewsky, M., Mary, I., Lecaque, D., Tournemine, C., Secchi, J. \& Deraedt, R. (1985) Pharmacological profile of RU 486 in animals. In The Antiprogestin Steroid RU 486 and Human Fertility Control, pp. 49-68. Eds E. E. Baulieu \& S. J. Segal. Plenum Press, New York.

Psychoyos, A. (1973) Endocrine control of egg implantation. In Handbook of Physiology, vol 2, part II, pp. 187-215. Eds R. O. Greep \& E. B. Astwood. American Society of Physiology, Washington, DC.

Psychoyos, A. \& Prapas, I. (1987) Inhibition of egg development and implantation in rats after postcoital administration of the progesterone antagonist $\mathrm{RU}$ 486. J. Reprod. Fert. 80, 487-491.

Sarantis, L., Roche, D. \& Psychoyos, A. (1988) Displacement of receptivity for nidation in the rat by progesterone antagonist RU 486: a scanning electron microscopic study. Hum. Reprod. 3, 251-255.

Scatchard, G. (1949) The attraction of proteins for small molecules and ions. Ann. N.Y. Acad. Sci. 51, 660-672.

Van der Schoot, P., Bakker, G. H. \& Klijn, J. G. M. (1987) Effect of the progesterone antagonist RU 486 on ovarian activity in the rat. Endocrinology 121, 1375-1382.

Received 24 June 1988 